\title{
Transition of the Health Care System and Sustainable Economy - Case Study for Serbia
}

\author{
Sofija Adžicí ${ }^{1}$ Jasminka Adžic ${ }^{2, *}$ \\ ${ }^{1}$ Faculty of Economics, University of Novi Sad, Segedinski put 9-11, 24000 Subotica, Serbia \\ ${ }^{2}$ School of Medicine, University of Belgrade, dr Subotica 8, 11000 Belgrade, Serbia \\ *Corresponding author: jaasna@gmail.com
}

Received November 29, 2012; Revised February 3, 2013; Accepted February 15, 2013

\begin{abstract}
This paper deals with the challenges of the health care system transition in the function of establishing a regime of sustainable economy in Serbia. The current system is not able to support this process, because a manipulative transition and a blend of quasy-public, quasy-market and administrative mechanisms of regulation made the existence of both public and private health care meaningless. The basic hypothesis is that the key task of the national health care system is to provide health care to every individual, so that he could cope with the challenges and problems of the development and operation of sustainable economy. Additional hypotheses are:(1) the production of medical goods and services must take place in the administrative hierarchical environment and (2) the main task of the public factors is the removal of barriers that block the adjustment of soft (software) elements of the health care system. In this context, the methodology for determining the transition model of health care can be defined as a process and activities that lead to adjustment of circumstances that cannot be changed, or competently act on those which can be controlled. Restructuring model of the health care system is defined as a mix strategy problems in which we need to solve the problems arising from the interactions of the: (1) health care system, (2) creation of humane conditions for establishing a regime of sustainable economy, (3) system of governance and (4) set of matching elements of education and innovation. A key result is that the solution lies in total re-engineering and in re-defining the justice paradigm. This way, the foreground of public health care system should be in prevention and preservation of health capabilities. Sophisticated and expensive technologies should be left to the private sector, based on the mix of public and private participation.
\end{abstract}

Keywords: Serbia, Sustainable economy, Health care system, Unclear, hazy and manipulative transition, Justice

\section{Introduction}

Serbia entered into a period of renovation of capitalism and (post-socialist) transition with the developed model of the "welfare state" which, in the given material limits, provided a high level of health care to the entire population. The national version of the "welfare state" was marked by the socialist character of the political and economic system, but its foundations date back to the past and are related to the results of the revolution carried out at the beginning of XIX century. In the national liberation from the Ottoman government, also a social revolution was carried out, which abolished feudalism and established the basic institutions of so-called "peasant economy". In the interest of preserving and improving the national independence, the political elite gradually developed the institutional and physical infrastructure, which, despite the overall poverty conditions, secured a certain minimum of health care for the majority of the population of Serbia. Serbia also early accepted a socalled "Bismarck`s model" of health insurance. In the period after the Second World War the health care system has gone through several stages in its development. In 1970 a right to an equal scope of health care for all citizens was introduced [5].
The problems in health care system functioning in Serbia started in the early eighties of the last century, when quietly began the collapse of socialism. Because of the method of financing of the public spending, the health care continued with the ostensibly development, but already at the end of the ninth decade of the last century the discrepancy between standardized health care rights and possibility of their funding from public sources has become apparent. Change of ruling ideology, made in the early nineties of the last century and the renovation of capitalism expressed as developmentally unproductive, because everything else has remained the same: work methods, approaches, value and attitudes [10]. The main features of the current socio-economic moment are the wrong socio-economic stratification and institutional disorder [2]. The reflections on the health care system are multiple. First, a space for wild privatization of (part of) public health care system and development of irregular partnership between the public and private sector in the production of health goods was opened [4]. Second, creation and development of a complex distributionoriented coalition was encouraged, which skillfully used its own political and any other influence to keep the situation as it was and stop the structural changes in the health care system and the regular development of private sector. Third, in terms of unclear, hazy and manipulative transition a mixture of quasi-public, quasi-market and administrative mechanisms of regulation, which made 
pointless the need for existence of public but also a private health care system, was created $[3,4,24]$. Therefore, solving the problem of health care system crisis and placing it into the function of development of a sustainable economy in Serbia is, above all, a matter of good (correct) understanding of the problem, and only then creating appropriate solutions. Let's see: "What are the fundamental limits in terms of creating conditions for development of sustainable economy in Serbia?".

The first is the socialization of economic risks for the disease at the workplace. A large number of working places and micro-environments where a work process takes place are created in a way that they directly endanger the health. In the current system of health and social care are not embedded the real economic motives and administrative constraints, which would force economic subjects and employers to, with technical improvements, resources and specialized training, reduce the health risks in the workplace at the socially acceptable limits [3].

The second is a consequence of the development of the specialized secondary and tertiary (and thus very expensive) infrastructure for health care in the public sector. Sectoral division shows a number of deficiencies: (1) fragmentation of health services and broad introduction of clinical specialty, (2) absence of continuity in the production of health goods, (3) uneven quality of service, (4) excessive use of higher levels of protection, (5) formal approach in promotion of health and disease prevention, particularly alcoholism, suicide, nutrition disease, smoking disease, drug abuse and AIDS, (6) neglecting the role of family as an important factor in health care, low status of primary health care, in terms of internal and external reputation of the medical profession, and so on $[4,8,22,23,25]$.

The third is a result of institutional arrangements of privatization of health care goods production [11]. Development of private sector in Serbia is carried out in terms of the so-called "passive privatization", influenced by the needs for higher quality of service than those provided by the public sector. Strengthening of private factor is induced, primarily, by constraints in servicing the provided rights. Rapid acquisition of wealth and poor control of work and revenues resulted in increase of private practices, dental and pharmaceutical institutions and specialized clinics. Very little relevant data exists on their business and effects on health care, but it is clearly that the private health care system has significantly affected the availability and equity in health care, in particular, due to the mass phenomenon that doctors and other medical staff identify and redirect patients to their own or another's private practice during their work in the public sector, although they should treat them just as well with less cost in their working hours.

Most of the key actors of health care system, like politicians, researchers and experts, including the foreign factor, solutions for overcoming these problems see in: (1) revitalization of the existing network of health care system capacities based on the program of reconstruction and modernization of existing facilities, purchase of new equipment, sales or renting the extra space and rationalization of employment and (2) defining the new model of payment to health care providers [12,20,21]. The main features of the official strategy, which is carried out since mid 2001 are the attempts to: (1) open a space for the reduction of public expenditure on health care in the gross domestic product (from about average $6.0 \%$ in the period $2001-2010$ to $5 \%$ in the period 2011 - 2020) by the model of reforms realized in other (post) socialist countries and (2) delay transparent, accurate and clearly defining role of private sector in the health care system, especially in the domain that would be covered by public funds $[13,14]$.

The objectives and actions of the current model of health care transition in Serbia, were derived from the uncritical transfer of reforms in the Member States CEEC10 as part of their preparations for European integration. $[12,13,14,15,16]$. Their essence was based on nonconsistent mix of recommendations of the joint institutions of the EU and the IMF, where in the forefront was the request for the reduction of public expenditures and transfers of health care costs to the individual and his family. From the aspect of Serbia, there is no doubt that some of elements mentioned above had a real socioeconomic and scientific foundation, and that the reforms in the national health care system are necessary, but it is an open question, what is their potential in creating conditions for the development of a sustainable economy. The realization was not accompanied by adequate information on how the change affected the improvement of the quality of health care products and if they had met the expectations of users (patients, customers to whom some subspecialistic services were inaccessible and vulnerable sections of society: unemployed, elderly, disabled, Roma). Low scores of national health care system quality in late 2011. that were measured on a sample of 34 European countries indicate that the effects of the reforms are not significant $[17,25]$.

Overflow of the first and second wave of the global financial and economic crisis, gave new meanings to the problem of the national health care system transition. Serbia, as its whole international environment, is faced with a request that in the next ten to fifteen years has to create the socio-economic framework for establishing a regime of sustainable economy. Because of the specifics that go beyond this paper, Serbia has to find answers to the challenges of sustainable development in the economy in which there is no clear vision of what kind of society, economically and socially speaking, its population is in ten to twenty years going to be living in and how it will survive and preserve its potential, year after year, to the creation of the minimum economic and social conditions to reach those goals. In the absence of this vision, many elements of political, economic and social realities seem disorganized, wrong and hasty. In this sense, the fate of the implementation of the concept of sustainable development of the economy in recent years can be determined. The Strategy for sustainable development, modeled by the ones in the desired environment, was adopted in Serbia in 2005. Its contents, in a formal sense, can be considered scientific and socio-economically acceptable. However, implementation has been reduced to partial actions related to waste management, which were primarily influenced by foreign factors, who wanted to enter a new and immature market without competition (these experiments were unceremoniously ended by national and international actors for reasons beyond the scope of this paper), and a marketing campaign of one party under the motto "Clean Serbia". And, in this case, it was confirmed that the national political, economic and 
intellectual elites often and easily make scientifically valid development goals and leave them even easier without full explanation and consequences for their creators. It seems that, in Serbia, it is not possible to determine the (development) vision because too much energy is used to maintain or win enormous power and royalties (which include the visible phenomenon of party-colored distribution management functions in public health institutions after each election).

\section{Materials and Methods}

The transition process of socio-economic systems can be understood in different ways, but in the case of health care system, scientifically valid meaning is its treatment as a transient process, which creates conditions for the revitalization of its functions in terms of generating new knowledge and skills with their valorization into organizations, processes and goods in a way that brings economic benefits and personal satisfaction to their creators and actors and new values (in terms of development and improvement of mental, emotional and physiological parameters for the good life and work) to the user. In this context, the preparation and implementation of health policy as the main instrument of public regulation of health care system, aims to initiate, enable, encourage or discourages the certain forms of its transition. Health care system transition management is being realized, as with all other (socio-economic, physical and technical) systems, by: (1) acting on the input parameters, in order to obtain the desired output, or the state of the system, or (2) acting with the aim to maintain the state of the system, due to changes in its environment. In both cases, the transient appears. Since the health care system operates in a constantly changing environment found practically always in a transitional regime, which, in terms of themes, can be defined as a form of evolutionary transition caused by radical changes in the public governance system. At this point, it is important to note that the transition problems in the physical and technical systems are the subject of detailed study for a long time and that the fundamental problems of their reliability are mainly related to the phenomena that occur in transitional regimes. In contrast, the economic and organizational theory pays relatively little attention to the problem of transients or to the transition of large socio-economic systems. Most of the research effort has been directed to the phenomena that occur in the permanent regime, or identifying and explaining the relation $\mathrm{y}=\mathrm{f}(\mathrm{x})$. Because of this there is a lack of knowledge about the phenomena of large socio-economic systems transition, such as: (1) inertia in terms of indifferent behaviour of actors and users to the changes in transition, (2) resistance to changes in transition, (3) adaptation to changes in transition, (4) needs for changes in content of goals during the clearly targeted transition, (5) stability or instability of the socioeconomic system in transition, (6) linearity or nonlinearity of the socio-economic system in transition, and in particular, (7) time duration constants of certain phenomena in transition process.

In this context, the basic hypothesis of this paper is that the problem of health care system transition in Serbia should be placed in function of creating conditions for implementation of developmental, economic, social and business paradigms, which mark sustainable economy, of which for the topic is most important the development based on (scientific) knowledge in order to increase exports with a higher share of added value per unit of product in terms that ensure the preservation and improvement of social, cultural and ecological values for present and future generations. In the level of operationalization, the main task of the health care system is that the in reliance on an educational system provide to each individual who wants it, the level of medical fitness, knowledge, skills and culture of life and work with which they will be able to cope with the problems of development and functioning of a sustainable economy. The current health care system in Serbia is not able to support this process because, according to the axioms of economy of bureaucracy, it produces goods by structure, quality and cost, primarily, as per own discretion (supply push approach), and with a little with delay compared to the needs of individuals, their families, public and business sectors for health (demand pull approach).

The second hypothesis is that the production of health care goods and services, as a mix of public and private goods, in conditions of market economy model, takes place in an administrative hierarchical environment $[3,4]$. In this environment, there is a centre or command authority which determines: "What, how much and under what conditions should be produced?". Management (leadership) of public health institutions has been authorized, and in private institutions forced to in these frames produce more and rigorously respect the imposed limitations. Accordingly, the essence of efficiency is that the public and also the private health institutions operate in institutionally regulated environment, which defines: (1) a minimum of what must be provided from health goods, (2) standard qualities of health goods and (3) prices and conditions of their extended reproduction, as the basic elements of feedback, for which should be found solutions for social-economic phenomena, (4) anticipation of demand for health goods in the short, medium and long term, (5) selection of the level of gratification of demand for health goods at national, regional, sub-regional and local level, based on the criteria that their distribution is performed at the level of the individual, in accordance with some publicly, precisely and clearly defined minimal requirements, (6) evaluation of the situation and possibilities of using capacities to produce health goods and (7) determining the relationship between the national, regional, sub-regional and local investment policy. In this context, the reforms of the health care system give economically and socially superior solutions only if the appropriate combination of institutionally regulated environment and market mechanism are ensured. In this sense, according to the author's opinion, the task of the strategy of the health care system transition is also the search for answers to the questions: (1) "What are the basic characteristics of institutional disorder?" (2) "What should be done on performances improvement?", and (3) "How to provide more intelligent action of public regulation in the sphere of improvement of their performances?"

In this context, the basic characteristics of the process of finding the right goals and actions of the health care system transition are: (1) multi-criterion of the problems that to be solved, (2) a better understanding of transient phenomena, in particular, resistance to changes which 
marks the process of reconstruction and performance improvement, and (3) instability of social preferences in determining the scope, structure and quality of health care goods that are financed from public funds.

On the other hand, the improvement of their performance is a complex socio-economic phenomenon. It is at the same time linked to the decision making about the distribution of the rights on (minimal) living and working conditions, and public and commercial entities business, fiscal pressures, public spending, changing the structure of reproduction, or personal consumption, employment, modernization of technology, public and private investments, import and export. Accordingly, the problem of improving the performance of health care system is primarily a matter of human creation, or its essence to understand the risks behind every (public) decision. Improving the performance of health care system cannot be done without building an efficient infrastructure for public regulation and integrated market system in accordance with the paradigm of a sustainable economy. However, the transition of health care system cannot wait for their completion and structural adjustment. Development of public and market institutions and improvement of performances should be made in parallel, on the go.

Accordingly, the third hypothesis of this paper is that the main task of the public factor in improving performance of health care systems is in the function of sustainable economy development - removing barriers that block the adjustment of so-called soft (software) elements, such as: (1) changes in the power structures between the internal and external factors, with emphasis on the making a precise public and transparent framework for the public regulation of health organizations behaviour, which operate in the regime of administrative and natural monopolies (2) improvements in regulatory circles and in rules for performing the key process in the production of health goods, (3) adjusting the general frameworks that define the role and economic status of employees in the health care system and (4) development of organizational culture (health goods and services production in public and private sectors as public goods - note by the authors!) that will ensure the quality of content of typical behaviour rituals of employees in order to efficiently meet the needs of the users of health goods [3,9]. However, before a detailed interpretation of the proposal of essence and method of transition of health care system in the function of development of a sustainable economy in Serbia, we will try to shed light on some essential aspects of institutional disorder problems.

Analysis of the (current) institutional disorder on the structural adjustment of the health care system in the function of development of a sustainable economy in Serbia, took place in the context of basic socio-economic challenges [7,21,24]. These are: (1) Changes in the demographic structure of the population, which caused corresponding displacements in the structure and scope of private and public consumption and demand. The emphasized tendency of aging population has resulted in dynamic growth in demand for specific goods of health and social protection, which cannot be clearly and accurately distinguished between these two sectors, (2) Changes in the pattern of life and consumption put a greater emphasis on the problem of the quality and content of health care goods in accordance with the specific needs of the individual and individual participation opportunities, so the communication, in terms of recognizing the real needs and economic possibilities of individual and specific socio-economic groups has become one of the key factors for the efficient production of health goods, (3) Deregulation has eliminated the administrative barriers for the entry of private sector in the health care system, and opened a space for partnership between the public and private sectors, and for increasing the role of private participation in financing the cost of production and expanded reproduction of health goods, (4) Growing innovative and software content, as well as the problem of complex linkage of causes of poor health due to no synchronism between new health needs and challenges and public and market regulation of health, educational and social spheres significantly narrowed the possibility of providing health goods on the principle "equal rights for all", (5) Strict functional and territorial division of labour in the production of health goods are replaced by their integration and specific forms of horizontal and vertical decentralization. (6) A large socio-economic structural changes, chaos and lack of ethical standards have opened a space for the expansion of the "shadow" economy, corruption and various abuses and frauds, (7) In order to successfully meet the challenges from (1) to (6) organization and management of health care institutions formed for economies of scale and uniform content of appropriate health good, should be replaced by the organization and management for the economy of flexibility, scope, time and innovations. Therefore, the boundaries between some functions of tightly structured organizations of health care system are becoming less sharp and clear, and the creative job done and the introduction of a multidisciplinary linkage with educational, social and cultural spheres become the basic criteria for measuring the efficiency and the development of strategic, technological and other alliances at the local, sub-regional and regional level on the basis of cooperation between the public and private sectors are becoming a necessity.

In the context of these three hypotheses a methodology is chosen to determine the model of health care system transition in order to create the necessary conditions for constituting the development of a sustainable economy regime in Serbia (as set of requirements listed in the previous paragraph from (1) to (7)), as a process composed of activities, which lead to adjustment of the conditions, which can not be changed, or competently act on everything what can be controlled. In this framework, two key methodological approaches are specially separated.

The first is related to the problems of retrospective and prognostic studies of links between the health care system transitions, role of educational system and innovation in its restructuring and improvement, role of the public management system and creating conditions for the development of a sustainable economy. The nature of these paradigms is such that the use of own and others' experience is very limited. Let's start with a key factor the health care system transition. The number of factors is large, but the most important ones are: science (in terms of generating new knowledge and skills), education (in terms of transfer of new knowledge and skills), entrepreneurship and practical experience, as well as the creation of knowledge and skills by work. The role of the public 
management system is to allocate labour and entrepreneurship related to these knowledge into projects for improving health care, which will provide a high level of mental, emotional and health ability to face the challenges of life and work to every individual, who wants it. If we could identify what kind of public governance we need and which knowledge and skills should be produced and how would we pass them to the actors and users, we would also have available key information on what type of health care system Serbia needs. This raises the question of the purpose of searching for a model of health care system transition in order to create conditions for the development of a sustainable economy. What is known are the partial models (jobs) of providing health care, which have been abandoned, and also those which now have priority and whit what type of education, management and innovation was needed for their establishment, development and introduction into the general practice. On the other hand, there are more or less reliable predictions regarding the partial works (models) of health care in the near and distant future. Repercussions on the methodology for determining the health care system transition is a choice between three approaches.

The first approach is consciously guided strategy of health care system transition based on ex-ante set goals (normative or intended strategy). It is based on prediction, solid management and good quality control. Problems could arise when in the future some of the ex-ante targets prove wrong or mechanisms for their implementation proves ineffective. The second approach is based on the fine-tuning of the health care system to the needs of the current situation. This approach is often used in small and less developed countries, such as Serbia. The basis is in the claim that the future is in the present of developed countries, and accordingly, that undeveloped ones may adapt their experiences in the development of the health care system. The main consequence is the constitution of imitative health care system. The key problem is the overproduction of health institutions, which are not followed by adequate possibility to apply the appropriate knowledge and skills to the users of the health care system, or their implementation by the vague and non-transparent criteria. The third approach can be characterized as a process of growing (proactive, reactive) strategy of health care system development and, as a strategy, which can be achieved despite or absence of intention. Mostly relying on this strategy can lead to chaos in the health care system. The advantage is that in the case of rational behaviour of management key actors and development under conditions of uncertainty (which is the normal behaviour of the entrepreneurs and leading management of commercial enterprises in the market economy - note by the authors) an unmeant state of health care system may occur, which is more suitable to the requirements of the overall socioeconomic environment.

These three processes are extreme, and in real-life situations we can only talk about the mix of intended, imitative and growing strategy of education system development. What are their implications on the proposed methodology?

1. The objectives and mechanisms for implementing elements of the strategy of development of the health care system should be clearly, accurately and transparently define so that they can be determined reliably or fully controlled, and, accordingly, the (sub) structure of the health care system should be determined, which will accept their successful implementation.

2. The parameters (for example, requirements in terms of adaptability, flexibility, rigidity, etc.) should defined for the elements of the strategy for the development of the health care system, which development and operation can not be reliably predicted, and, accordingly, the (sub) structure of the health protection should be determined and be based on the principle of rationality in seeking for solutions in an unstable and uncertain circumstances.

3. In both cases, the learning function should be incorporated into the corresponding (sub) structure of the health care system (in the sense of ability to learn about them and on this basis take corrective action). This primarily applies to those which are determined to define and realize the strategies.

4. In accordance with (1), (2) and (3), the strategy of the health care system development should be defined as a combination of intended (pre-formulated) and growing (responsive, adaptive) strategy, in which elements of imitative strategies should be also included, especially in terms of determining high standards in concretization of some goals or determining of the moment to access the reaction.

Second methodological approach is derived from the request for more accurate and transparent determination of goals and action of strategies for structural adjustment of the health care system in order to create conditions for the development of a sustainable economy. Prognostic research of this strategy is very complex and delicate, because the nature of sustainable standards makes the use of historical experience very limited. Their relationship is not direct - it is achieved by using the system of public regulation (in terms of the obligation of the state to direct the health care system towards the implementation of sustainable economy standards). Thus the proposed methodological approach introduces a triangle made up of the interactions between:

$\mathrm{WS}=$ health care system,

$\mathrm{SE}=$ creation of conditions for sustainable economic regime, and

$\mathrm{PM}=$ system of public governance (in terms of the constitution of an appropriate institutional framework and good practice of public action).

Key factors for their efficient linking are education and science (more precisely knowledge), skills and experience in generating innovations in health care in a way that will bring new values to both users and innovators (with the emphases on their role in (a) individual training of actors in public management and production of medical goods, (b) improving the organization and technology in the health care system, and (c) exploring new models of funding of health care system acceptable to users and taxpayers - author's note). Therefore, the triangle is transformed into a rectangle by inclusion of complexes composed of the relevant parts of the education system (what, where and how should one be taught in order to realize the necessary reforms and structural adjustment) and innovation (especially in the field of creative solutions for the restructuring of the existing structure of institutions and their distribution according to demographic changes) as well as models for their restructuring. Since these are the elements that belong to the system of continuous education and generation of innovation on the principles of application, testing, modifying, or vacating on, they 
should be considered as an integrated system (EI = education + innovation system).

The question arises: "What is the intensity of the interaction between these four phenomena?" Since these are the sizes that vary in time, time delays are inherent. Therefore, certain dependencies were determined for three different periods characteristic for development of Serbia: (1) $\mathrm{LT}=$ past, the period since 1947. to 1990. (period of operation and development of health care in accordance with the basic axioms of socialism), (2) PT = present, the period since 1991. to 2012. (period of transition of the health system in accordance with the concept of building a market economy and its socio-economic superstructure) and (3) FT = Future, the period from 2013. to 2030. when the completion of shaping of the framework for the development of a sustainable economy in Serbia is expected. The results of the application of this framework are given by the matrix of interdependence (Table 1). The intensity of the interaction is determined on the basis of an expert assessment by three steps: $1=$ poor, $2=$ important, $3=$ key. Initial determination is the estimation of how much does the observed phenomena (for example, Public Management (PM)) from the past (LT) influence the state of other phenomena (for example, health care system (WS)) in the present (PT), or how much it will influence it in the future (FT). These estimates are valid for Serbia in the period from 1947. to 2030. and within the same subperiods. Due to similarities to problems of redefining the role of health care in establishing a regime of sustainable development in countries in the immediate region (Western Balkans, which include Albania, Bosnia and Herzegovina, Croatia, Montenegro and the Former Yugoslav Republic of Macedonia), the application of this part of the methodological approach would reproduce the same results in this countries as well, especially in regards to the past (LT) and present (PT). Estimates for the future should be examined in other contexts, since it is obvious that they will follow (partially) divergent directions.

\section{Results}

A key determinant in presented methodology is that the strategies of health care system transition in function to create conditions for development of sustainable economic in Serbia must be defined as a mix of normative and growing strategies. From the aspect of weak capacity of the management system in Serbia, it is desirable that the initial parameters have (mostly) normative characteristic in order to start reforms in right direction. This faces us with two problems. The first is that no matter how slowly the structural changes in the health care system are going, the supporting of the conservation of state in this system makes the trajectories in the future unpredictable. This also includes the consequences in case of (scientifically) undesirable option of total destruction of the public health care system because of the inability to finance the institutionally arranged rights to health care. This would bring into the question the justification for the existence of a large number of its institutions (which is otherwise partly opened with the renovation of capitalism). The second is that the strategy of health care system transition can not be based only on the normative (intended) approach (derived from the model of present of societies and economies in targeted European environment), but also on the concept of growing (proactive, reactive) strategy, in which the elements of imitative strategy are involved, as part of framework, which should more precisely and transparently lead to improvement of health care system functions. Since Serbia, as noted, is for long time in a period of growing uncertainty in terms of possibility of implementing the scientifically recommended concepts of socio-economic development and the scene of conflicts between numerous groups of special interests, the realistic solution is that the development of the core of health care system follows the concept of intended strategy, and other parts, the concept of emerging strategy.

At the same time, in the determination of the strategy of the health care system transition in function of constituting framework for establishing a regime of sustainable economy, the results of an application of methodological approaches to determine the intensity of interactions in four-square: health care system - public management - creating conditions for the development of a sustainable economy - educational and innovation system and their implications for the transition of the health care system in Serbia should be taken into account. The dimensions of this problem can be approximated by the number of direct and indirect interactions between listed (sub) systems. This number is high. For example, the number of direct interactions between the (sub) system of health care and the other three (sub) systems is 68 (Table no. 1), while the number of indirect is even higher (for example, the current results of health care system will have a great impact on the future state of the management system, which will have a major impact on the future state of the program of constituting the conditions for the development of a sustainable economy in Serbia). Therefore the reductions were carried out.

Table 1. Matrix of interdependence: WS - PM - SE - EI in Serbia

\begin{tabular}{|c|c|c|c|c|c|c|c|c|c|c|c|c|c|}
\hline & & \multicolumn{3}{|c|}{ WS } & \multicolumn{3}{|c|}{$\mathrm{PM}$} & \multicolumn{3}{|c|}{ SE } & \multicolumn{3}{|c|}{ EI } \\
\hline & & $\mathrm{L}$ & $\mathrm{P}$ & $\mathrm{F}$ & $\mathrm{L}$ & $\mathrm{P}$ & $\mathrm{F}$ & $\mathrm{L}$ & $\mathrm{P}$ & $\mathrm{F}$ & $\mathrm{L}$ & $\mathrm{P}$ & $\mathrm{F}$ \\
\hline & & $\mathrm{T}$ & $\mathrm{T}$ & $\mathrm{T}$ & $\mathrm{T}$ & $\mathrm{T}$ & $\mathrm{T}$ & $\mathrm{T}$ & $\mathrm{T}$ & $\mathrm{T}$ & $\mathrm{T}$ & $\mathrm{T}$ & $\mathrm{T}$ \\
\hline \multirow{3}{*}{$\begin{array}{l}\mathbf{W} \\
\mathbf{S}^{1}\end{array}$} & $\begin{array}{l}\mathrm{L} \\
\mathrm{T}^{2}\end{array}$ & & & & $1^{3}$ & & & 2 & & & 2 & 1 & \\
\hline & $\begin{array}{l}\mathrm{P} \\
\mathrm{T}\end{array}$ & & & & & 1 & 1 & 1 & 1 & & & 3 & \\
\hline & $\begin{array}{l}\mathrm{F} \\
\mathrm{T}\end{array}$ & & & & & 1 & 3 & 1 & 1 & 3 & 1 & 1 & 3 \\
\hline \multirow{3}{*}{$\begin{array}{c}\mathbf{P} \\
\mathbf{M}\end{array}$} & $\begin{array}{l}\mathrm{L} \\
\mathrm{T}\end{array}$ & 1 & & & & 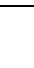 & & 1 & & & 1 & & \\
\hline & $\begin{array}{l}\mathrm{P} \\
\mathrm{T}\end{array}$ & & 1 & 1 & & 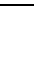 & & & 1 & 1 & & 1 & 1 \\
\hline & $\begin{array}{l}\mathrm{F} \\
\mathrm{T}\end{array}$ & & 1 & 3 & & & & & & 2 & 1 & 1 & 3 \\
\hline \multirow{3}{*}{ SE } & $\begin{array}{l}\mathrm{L} \\
\mathrm{T}\end{array}$ & 2 & & & 1 & & & & & & 2 & & \\
\hline & $\begin{array}{l}\mathrm{P} \\
\mathrm{T}\end{array}$ & 1 & 1 & & 1 & 1 & & & & & 1 & 1 & \\
\hline & $\begin{array}{l}\mathrm{F} \\
\mathrm{T}\end{array}$ & 1 & 1 & 3 & 1 & 1 & 3 & & & & 1 & 1 & 3 \\
\hline \multirow{3}{*}{ EI } & $\begin{array}{l}\mathrm{L} \\
\mathrm{T}\end{array}$ & 2 & & & 1 & & & 2 & 1 & & & & \\
\hline & $\begin{array}{l}\mathrm{P} \\
\mathrm{T}\end{array}$ & 1 & 1 & & & 1 & 1 & & 1 & 1 & & & \\
\hline & $\begin{array}{l}\mathrm{F} \\
\mathrm{T}\end{array}$ & & 1 & 3 & 1 & 1 & 3 & 1 & 1 & 3 & & & \\
\hline
\end{tabular}

${ }^{1}$ WS-health care system, SE- creation of conditions for sustainable economic regime,

PM- system of public governance

${ }^{2}$ LT-past, PT-present, FT-future

${ }^{3} 1=$ poor, 2 = important, $3=$ key 
The first is carried out from an analysis of direct impact on health care (sub) system in the period from 2013 to 2030. The analysis suggests that the health care (sub) system will be under: (1) the decisive influence of events in the management (sub) system, framework for establishing a regime of sustainable economy development and the corresponding parts of the education and innovation system in the period from 2013 to 2030, (2) a significant influence of the events in the management (sub) system, framework for establishing a regime of sustainable economy development and the corresponding parts of the education and innovation system in the period 1947-1990, and, above all, in the period up to 2020, after which will come to an abrupt weakening of their influence, and, practically, disappearance till 2030, and (3) small (in the positive sense of the term) influence of events on the management (sub) system, framework for establishing a regime of sustainable economy development and the corresponding parts of the education and innovation system in the period since 1991 by 2010. This is a consequence of transitionalism, which was followed by radical reduction of social wealth and devastation of human capital, whose analysis is beyond the scope of this paper.

The second reduction is based on the separation of interaction, which will have a direct role in forming the strategy of the health care system transition in the function to the realization of the project of constituting a framework for establishing a regime of sustainable development in Serbia till 2030. Separated are only those whose development can be predicted (in terms of - how will going the state of affairs in the future on science preferred method). These are: (1) the current state of the health care system, and (2) the future state of requirements for improving the framework to guide the process of constituting the regime for the development of a sustainable economy in a scientifically given direction, which must necessarily be preceded by changes in the functioning of the management (sub) system and related parts of educational and innovation system.

\section{Discussion}

The presented analysis indicates that for the increasing the efficiency of health care system in order to create a framework for the development of a sustainable economy in Serbia relatively radical changes in the structure of government and society are needed, so that its transition could be directed into the right direction. The key to these changes is establishment of a consensus between the political and economic elite and the majority of the population of Serbia in the role of the state in the sphere of health care. The potential interest of political and economic elites is to by increasing the efficiency of the health care system ensure a political and social stability needed for their legal stratification. On the other hand, the interest of the majority of the Serbian population in the given material context is to ensure the best possible conditions for health care. But the real state shows that within the political and economic elite dominate those who do not see their interests for establishing a more precise and transparent concept of health care system reform in Serbia. Leaving aside the structure of interests which are behind this constellation, a (fourth) hypothesis can be set stating that a total re-engineering for the realization of successful reform of national health care system is needed [3].

Total re-engineering can be determined as an ambitious, radical, qualitative and on innovations relied methodology that would, on the basis of developmental vision, set the direction of institutional changes and a variety of reforms in order to transfer the existing resources of the health care system in the state in which in the foreground are orientation on prevention and preservation of medical fitness (of entire national population) on the basis of development of an appropriate system of life and work, while the treatment of the diseases for which sophisticated and expensive technology is used, should be left to the private sector based on the mix of public and private participation. The key to the implementation is in the new definition of the content of paradigm of justice.

The ruling paradigm that the public health insurance should provide the best health care to everyone is false and financially unsustainable for a much richer societies of Serbia [4, 24, 25]. On the other hand, the justice means providing the health care within the public, transparent and precise minimum standards for all (meaning that no one should die because he/she is not insured, because there is no money for treatment, or simply, as is often the case in Serbia - because they don't not know the right people). In this sense, in order to create the conditions for liberal structuring of content of distribution of production costs to health goods between the public and private factors, and which the population will accept as a legitimate replacement for their providing according to the concept of welfare state, it is necessary to substitute the factor institutional disorder with smarter public factor action in the function for improving the micro-efficiencies in their production.

Accordingly, three basic directions of the reform of public factor functions in strategic management and development of the health care system are imposed.

First are the decentralization and de-concentration of public administration responsible for the regulation of the behavior of public and commercial organizations which produce health goods and services. The main goals are to make service approachable and to provide flexibility. The current distribution of the right to public health care services and goods is subject to very complicated and lengthy administrative procedures. In cases where the user needs or wants to get a good health case outside the administrative district of his/her residence, there is a high risk that he/she will be rejected. In order to create the conditions for de-concentration and decentralization, an uniform pricing for public health goods and services should be established based on the legitimate standards of services. The user should have the right to use the services in the whole territory of Serbia, and (eventually) to pay the difference in accordance with his/her choice. Freedom to (administrative) access to services should be provided directly trough information systems and by using precise, clear and transparent procedures. This would simultaneously create conditions for reducing the high cost of oversized network of institutions and administrative procedures, and for decentralization and de-concentration of the functions of public administration. Second is the introduction of a system of continuous improvement of health services quality in order to satisfy the differentiated needs of users, by taking over the 
business techniques and orientation to individual expectations and additional resources for their providing. Third is the improvement of regulatory mechanisms: improving the quality of legal regulations of public and private sector, reducing the costs of implementation and improving the system of monitoring and performance control, by taking over the appropriate business techniques.

In any case, the proposed concept of the national health care system transition and policy for its operationalization may seem pretentious. To overcome this problem, the real state in which the content modelling of the actions of reform of protection system is done should be marked as problematic, while the methodology and the process of its implementation should be marked as systematic. This approach is based on the model of political, economic and professional culture based on wide participation of those who are in any way involved in the resolution of problematic situations. In this sense, at first sight, it appears that the proposed approach is based on the idealistic assumption that cooperation will be achieved without the use of mechanism of coercion. This is, certainly, an area in which the basic limitations of its application are located. In particular, the (negative) national experiences in using specific hierarchically designed soft methodologies for economic and political regulation (based on a comprehensive consultation and agreement) are significant. Although the model of political, economic and professional regulation proposed in this paper is not based on the presented concepts, its implementation also required a certain culture of participation. However, because of neglecting of the existence of different subcultures and difficulties of their integration, the system of social consultation and agreement is as an instrument of the macro-management of future abandoned and replaced by mechanism of coercion.

The biggest advantage of the presented approach in modelling of the health care system transition is the ability to use a variety of corrective actions based on broad participation, with which the partial views and truths are involved in the search for the best solutions to overcome the specific problem. The paradigm learning based on multi-criteria compromise decision making in designing objectives and actions of reforms should provide the flexibility and robustness in determining content and implementation of the structural adjustment process of the public health care system, especially in terms of encouraging of its subjects on cooperation, that was not addressed. However, as open questions remain the problems of: (1) development of methodological procedures of multi-criterion analysis, and (2) development of multi-attribute analysis of utility, which would respect the fact that the decisions are made based on criteria that cannot be directly measured or compared.

\section{Conclusions}

In this paper an attempt was made to prove that the deterministic concept, in which the problem of financing the health care system is the main focus of public action, can not represent the exclusive basis for its reforms in the direction of constituting a framework for establishing a regime of sustainable economy development in Serbia. Functioning of the health care system as a large socio- economic system is at the same time predictable and unpredictable, stochastic and deterministic. In this context, the existential and developmental problems of health care system can be solved only by comprehensive consideration of all conceivable solutions and careful selection of the optimal. In this sense, the solution is in a complete re-engineering, as a form of ambitious, radical, qualitative and by innovations supported methodology that would on the basis of developmental vision, set the direction of institutional changes and different reform activities to transfer the great available resources of the health care system in the regime in which foreground are prevention and preservation of medical fitness (of the whole national population) on the basis of the development of an appropriate system of life and work, while the diseases treatment for which very sophisticated and expensive technology is used, should be left to the private sector based on the mix of public and private participation. The key to the implementation is in the new definition of the content of paradigm of justice.

The paradigm that the public health insurance should provide to everyone the best health care is false and financially unsustainable for a much richer societies than Serbia. On the other hand, the justice means a need to ensure the health care within the public, transparent and precise minimal standards for all. Accordingly, the presented concept of total re-engineering of national health care system is based on the activist approach in which the public factor in accordance with the basic division of responsibilities in the administrativehierarchical environment should find a good solutions for: (1) improving external and internal system of management and control, (2) restructuring the internal organizational structure, (3) improving the quality of labour, (4) withdrawal from activities that may be organized on a commercial basis and (5) creating a necessary capital base for revitalization and modernization - to rationalize the operations and to raise the quality of health goods in a socially acceptable level. This gives, to the process of increasing the efficiency of the public health care system, a high degree of subjectivity. In this context, the problem of improving the efficiency of the national public health care system remains open and will depend primarily on changes in perceptions of political and professional (medical) elite and on progress in making the concept of their social responsibility to the (minimal) European norms.

\section{References}

[1] Adžić, S. (2006) Social and developmental aspects of transition in Serbia (Socijalni i razvojni aspekti tranzicije u Srbiji), in "Ekonomski Anali", April (2006), pp. 327-339.

[2] Adžić, S. and Adžić, J. (2006), Modelling the Social Policy in Disordered Institutional Surrounding and Assessing Risks in Making Decisions - Study of the Case of Serbia, in: ISA XVI World Congress of Sociology "The Quality of Social Existence in a Globalizing World, (CD-ROM)", International Sociological Association and Faculty of Political Science and Sociology, University Complutense, Madrid, Durban, July 23-29, 2006.

[3] Adžić, S. and Šaša, R. (2006), Crisis Management and Rehabilitation of Companies Producing Public Goods, in "Serbian Journal of Management", Volume 1 Number (2). pp. 123-138.

[4] Adžić, S. and Adžić, J. (2007) Reengineering of the Public Healthcare System in an Institutionally Non-Regulated Surrounding - The Study of the Case of Serbia. In: "Creativity Imperative for Global Business and Development and Innovation: 
Processings of the 10th International Conference of the Society for Global Business and Economic Development (SGBED)", Volume II, pp. 1571-1586.

[5] Dovijanić, P. (1994), Health care and health care in the SFRY (Zdravstvena zaštita i zravstvena zaštita u SFRJ), Nolit, Belgrade.

[6] European Commision (2011), Europe 2020 - A strategy for Smart, Sustainable and Inclusive Growth, Brusels, Brusels: COM (2010) 2020, 3.3.2011.

[7] Filipović, M. (2010), Sustainable development of Serbia: Possibilities for its implementation (Održivi razvoj Srbije: Mogućnosti sprovođenja), in "Izazovi evropskih integracija: Tema broja: Održivi razvoj - ideali i realnost”, No 9, pp. 73-86.

[8] Gartfield, R. (2001), Economic Sanctions, Health and Welfare in the Federal Republic of Yugoslavia 1990-2000, Belgrade: OCHA and UNICEF.

[9] Kosanović, R. (2004). Reforms of the healthcare system implementable and concrete goals (Reforma sistema zdravstvene zaštite - Ostvarivi i konkretni ciljevi). Glas Osiguranika,13. Belgrade. Centar za proučavanje alternativa, Samizdat B92.

[10] Matejić, V. (2003). Contributions to scientific and technological research and development management organizations (Prilozi istraživanju naučnog $i$ tehnološkog razvoja i upravljanja organizacijama). Belgrade. Savezni sekretarijat za nauku i razvoj

[11] Simić, S., Kosanović, R. and Mladenović, D. (2001). Privatiyation in health care (Privatizacija u zdravstvu) in Osnove za reformu sistema zdravstvene zaštite. Belgrade. Centar za proučavanje alternativa, Samizdat B92.

[12] Study (1991): Organizacion and Financing of Health Care Reform in Coutries of Eastern and Central Europe, Geneve: WHO.

[13] Study (2001): Better Health for All in the Third Millennium (Bolje zdravlje za sve u trećem milenijumu), Belgrade: The Ministry of Health, Republic of Serbia.
[14] Study (2002): Health policy (Zdravstvena politika), Belgrade: The Ministry of Health, Republic of Serbia.

[15] Study, (2003): Serbia's strategy for poverty reduction: Government of Republic of Serbia.

[16] Study (2005): National strategy for HIV/AIDS in Serbia, Belgrade. The Ministry of Health of the Republic of Serbia.

[17] Study (2005): Human Development Report: Serbia 2005 - Power of diversity. World Bank.

[18] Study (2005): Serbian National Strategy for Accession of Serbia and Montenegro to the European Union, Belgrade: Serbian Government Office for European Integration.

[19] Study (2006). The National Economic Development Strategy of Serbia 2006-2012. Belgrade: Institute for Development.

[20] Study, (2008): National Strategy for Sustainable Development of Serbia, Belgrade: Government of Republic of Serbia.

[21] Study (2010): Post-crisis model of economic growth and development in Serbia 2011-2020, Belgrade: USAID, FREN and Economics Institute.

[22] Study (2010): Evaluation of the Organization and Provision of Primary Care in Serbia - A Survey Based Project in the Regions of Vojvodina, Central Serbia and Belgrade, Copenhagen: WHO Regional office for Europe.

[23] Vuković, D. (2005), Social security and social rights, Belgrade: Faculty of Political Sciences.

[24] Vuković, D. (2010), Social components of sustainable development in Serbia (Socijalne komponente održivog razvoja Srbije), in "Izazovi evropskih integracija: Tema broja: Održivi razvoj - ideali i realnost", No 9. pp. 41-54.

[25] Vuković, D. (2011), Pensions, Health Care and Long-term Care Republic of Serbia 2011, European Commission, DG Employment, Social Affairs and Equal Opportunities and GVG. 